Western University

Scholarship@Western

Medical Biophysics Publications

Medical Biophysics Department

$12-1-2014$

\title{
Anatomical, functional and metabolic imaging of radiation-induced lung injury using hyperpolarized MRI.
}

Giles Santyr

Western University, gsantyr@robarts.ca

Matthew Fox

Western University, mfox28@uwo.ca

Kundan Thind

Western University, kthind3@uwo.ca

Elaine Hegarty

Western University, ehegarty@robarts.ca

Alexei Ouriadov

Western University, ouriadov@imaging.robarts.ca

See next page for additional authors

Follow this and additional works at: https://ir.lib.uwo.ca/biophysicspub

Part of the Medical Biophysics Commons

Citation of this paper:

Santyr, Giles; Fox, Matthew; Thind, Kundan; Hegarty, Elaine; Ouriadov, Alexei; Jensen, Michael; Scholl, Timothy J; Van Dyk, Jacob; and Wong, Eugene, "Anatomical, functional and metabolic imaging of radiation-induced lung injury using hyperpolarized MRI."

(2014). Medical Biophysics Publications. 29.

https://ir.lib.uwo.ca/biophysicspub/29 
Authors

Giles Santyr, Matthew Fox, Kundan Thind, Elaine Hegarty, Alexei Ouriadov, Michael Jensen, Timothy J Scholl, Jacob Van Dyk, and Eugene Wong 


\title{
Anatomical, functional and metabolic imaging of radiation-induced lung injury using hyperpolarized MRI
}

\author{
Giles Santyr $r^{a, b, c, d *}$, Matthew Fox ${ }^{e},{ }_{f}$ Kundan Thind ${ }^{a, b}$, Elaine Hegarty ${ }^{a}$, \\ Alexei Ouriadov ${ }^{e}$, Michael Jensen ${ }^{f}$, Timothy J. Scholl ${ }^{a, b}$, \\ Jacob Van Dyk ${ }^{b, f, g}$ and Eugene Wong ${ }^{b, f, g}$
}

\begin{abstract}
MRI of hyperpolarized ${ }^{129} \mathrm{Xe}$ gas and ${ }^{13} \mathrm{C}$-enriched substrates (e.g. pyruvate) presents an unprecedented opportunity to map anatomical, functional and metabolic changes associated with lung injury. In particular, inhaled hyperpolarized ${ }^{129}$ Xe gas is exquisitely sensitive to changes in alveolar microanatomy and function accompanying lung inflammation through decreases in the apparent diffusion coefficient (ADC) of alveolar gas and increases in the transfer time $\left(T_{\mathrm{tr}}\right)$ of xenon exchange from the gas and into the dissolved phase in the lung. Furthermore, metabolic changes associated with hypoxia arising from lung injury may be reflected by increases in lactate-to-pyruvate signal ratio obtained by magnetic resonance spectroscopic imaging following injection of hyperpolarized $\left[1-^{13} \mathrm{C}\right]$ pyruvate. In this work, the application of hyperpolarized ${ }^{129} \mathrm{Xe}$ and ${ }^{13} \mathrm{C}$ MRI to radiation-induced lung injury (RILI) is reviewed and results of $\mathrm{ADC}, T_{\mathrm{tr}}$ and lactate-to-pyruvate signal ratio changes in a rat model of RILI are summarized. These results are consistent with conventional functional (i.e. blood gases) and histological (i.e. tissue density) changes, and correlate significantly with inflammatory cell counts (i.e. macrophages). Hyperpolarized MRI may provide an earlier indication of lung injury associated with radiotherapy of thoracic tumors, potentially allowing adjustment of treatment before the onset of severe complications and irreversible fibrosis. Copyright $\odot 2014$ John Wiley \& Sons, Ltd.
\end{abstract}

Keywords: hyperpolarized; MRI; lung injury; radiotherapy; diffusion; gas exchange; hypoxia; macrophages

\section{INTRODUCTION}

Lung cancer is the leading cause of cancer death in the world. $80 \%$ of all lung cancers are non-small cell lung carcinoma (NSCLC), which are often treated with thoracic radiotherapy (RT); however, the lung is a very radiosensitive organ and radiation-induced lung injury (RILI) is a common side effect. The incidence of RILI is reported to be $37 \%$, and of this population $20 \%$ are diagnosed with moderate to severe RILI (1). Coughing, fever and dyspnea have also been reported in 5-50\% of the RILI population (2). RILI

* Correspondence to: G. Santyr, Peter Gilgan Centre for Research and Learning, The Hospital for Sick Children, Toronto, Ontario, Canada.

E-mail: giles.santyr@sickkids.ca

a G. Santyr, K. Thind, E. Hegarty, T. J. Scholl

Imaging Research Laboratories, Robarts Research Institute, Western University, London, Ontario, Canada

b G. Santyr, K. Thind, T. J. Scholl, J. Van Dyk, E. Wong

Department of Medical Biophysics, Western University, London, Ontario, Canada

c G. Santyr

Department of Medical Imaging, Western University, London, Ontario, Canada

d G. Santyr

Peter Gilgan Centre for Research and Learning, The Hospital for Sick Children, Toronto, Ontario, Canada

e M. Fox, A. Ouriadov

Bay Regional Research Institute, Thunder Bay, Ontario, Canada can lead to temporary or permanent loss of lung function and in extreme cases death (3).

Clinical assessment and management of RILI utilizes both pulmonary function tests (PFTs) (e.g. spirometry, blood gases) and imaging techniques. Persistence of hypoxia as measured by the partial pressure of oxygen in arterial blood $\left(p_{\mathrm{a}} \mathrm{O}_{2}\right)$ has been reported post radiation therapy $(4,5)$, and recent studies suggest that it may further exacerbate lung injury (2). However, PFTs are whole-lung measurements and cannot identify regional deficiencies in lung function, which presumably reduces the sensitivity of PFTs to early injury. Imaging of RILI is typically performed using

\footnotetext{
$f$ M. Jensen, J. Van Dyk,E. Wong

Department of Physics and Astronomy, Western University, London, Ontario, Canada

g J. Van Dyk, E. Wong

Department of Oncology, Western University, London, Ontario, Canada
}

Abbreviations used: ${ }^{129} \mathrm{Xe}$, xenon- $129 ;{ }^{13} \mathrm{C}$, carbon- $13 ;{ }^{18} \mathrm{~F}-\mathrm{FDG}$, fluorodeoxyglucose; ${ }^{3} \mathrm{He}$, helium-3 (tralphium); ${ }^{60} \mathrm{Co}$, cobalt-60; ADC, apparent diffusion coefficient; COPD, chronic obstructive pulmonary disease; CSI, chemical shift imaging; CSSR, chemically selective saturation recovery; $C T$, computed tomography; DNP, dynamic nuclear polarization; Gy, gray; lac/ pyr, $\left[1-{ }^{13} \mathrm{C}\right]$ lactate to $\left[1-{ }^{13} \mathrm{C}\right]$ pyruvate signal ratio; NSCLC, non-small cell lung carcinoma; $p_{a} \mathrm{O}_{2}$, partial pressure of oxygen in arterial blood; $P E T$, positron emission tomography; PFT, pulmonary function test; RBC, red blood cell; RILI, radiation-induced lung injury; $R P$, radiation pneumonitis; $R T$, radiotherapy; SPECT, single-photon emission computed tomography; $T_{t r}$ transfer time; $\tau$, characteristic delay time; XTC, xenon transfer contrast. 
planar X-ray and computed tomography (CT). Although $C T$ changes have been observed before the onset of clinical RILI (6), these anatomical changes (e.g. lung density) often do not occur before clinical symptoms manifest $(7,8)$. In a previous study, RILI was detected using CT in roughly $75 \%$ of patients undergoing $\mathrm{RT}$, but not detected earlier than four weeks post RT (9). CT imaging of late-stage RILI is currently the gold standard for discerning fibrosis from lung tumor recurrence; however, it is often too late (several months) to effect any change in therapy to mitigate RILI. An imaging method sensitive to early (weeks) changes associated with RILI (i.e. radiation pneumonitis, RP) would be valuable to identify radiosensitive individuals and adjust therapy accordingly.

$X$-ray imaging methods are insensitive to functional changes associated with early RILI such as deficits in gas exchange, perfusion and ventilation, which are expected to occur well before anatomical changes. For this reason, nuclear medicine imaging techniques such as single-photon emission computed tomography (SPECT) and positron emission tomography (PET) can be used when functional lung information such as perfusion is required (10). Functional imaging with SPECT can provide ventilation and perfusion maps of the lung post injection of technetium-99 m (11,12). Studies have demonstrated a dosedependent reduction in perfusion and ventilation at 3-4 months post radiation therapy $(13,14)$. However, correlations between these metrics and whole-lung function assessed by pulmonary function testing (i.e. forced expiratory volume in $1 \mathrm{~s}$ and diffusing capacity for carbon monoxide) are weak and additional work is required to assess regional injury (10). Additionally, SPECT imaging is limited in spatial resolution, lacks specificity and provides $\sim 3 \mathrm{mSv}$ of extra whole-body radiation dose to the patient (15), which is approximately three times the annual background dose $(\sim 1 \mathrm{mSv})$ and $60 \%$ of the annual radiation worker limit( $\sim 5 \mathrm{mSv})$. PET imaging with fluorodeoxyglucose $\left({ }^{18} \mathrm{~F}\right.$ FDG) has shown increased uptake of ${ }^{18} \mathrm{~F}-\mathrm{FDG}$ associated with RILI in lung cancer patients (16); however, the technique is heavily dependent on tissue uptake of ${ }^{18} \mathrm{~F}$-FDG and is susceptible to a high false positive rate (17). In particular, high uptake of ${ }^{18} \mathrm{~F}-\mathrm{FDG}$ is associated with both inflammation and tumor growth, and no clear separation of RILI and cancer has been demonstrated $(18,19)$. As with SPECT, PET requires an acquisition time of approximately an hour and also incurs additional radiation dose to the patient ( $\sim 15 \%$ of the annual radiation worker limit).

In contrast to X-ray and nuclear medicine imaging methods, MRI provides an approach for probing lung anatomy and function without the use of ionizing radiation, which may be particularly well suited for tracking the progression and regression of the early stage of RILI. Conventional MRI (i.e. proton) approaches aimed at detection of RILI have been performed previously through the measurement of regional perfusion (20) and the $T_{2}$ relaxation times of lung tissues (21). However, proton MRI is challenging in the lung due to low proton signal, as it contains only approximately $20 \%$ soft tissue. This low signal is further diminished by the presence of microscopic magnetic field non-uniformities arising from susceptibility differences at the gas/tissue interface. Furthermore, respiratory motion can be problematic, leading to image blurring and other artifacts.

The issue of low MRI signal in the lung has recently been addressed by the advent of spin exchange optical pumping (i.e. hyperpolarization) techniques, which can boost the signal of certain inhaled noble gases $\left({ }^{3} \mathrm{He}\right.$ and ${ }^{129} \mathrm{Xe}$ ) by up to five orders of magnitude (22). High spatial resolution spectroscopic imaging can be achieved with hyperpolarized gas MRI, and it provides a wide palette of anatomical and functional biomarkers, which can potentially map RILI progression and treatment response including ventilation (23), perfusion (24), and gas exchange (25). In addition, a truly unique morphological lung measurement is possible using hyperpolarized gas MRI, namely the apparent diffusion coefficient (ADC), a surrogate for alveolar size. Some of these measures have already been investigated in patients with chronic obstructive pulmonary disease (COPD) (26-28), asthma (29) and cystic fibrosis $(30,31)$, as well as in animal models of lung disease $(20,24,25,27,32-36)$. More recently, ${ }^{13} \mathrm{C}$ has been added to the family of hyperpolarized nuclei available for use with MRI (37). The polarization of ${ }^{13} \mathrm{C}$ nuclei can be greatly enhanced in the solid state using dynamic nuclear polarization (DNP), in which certain ${ }^{13} \mathrm{C}$-enriched endogenous compounds may be prepared with liquid-state polarizations exceeding $20 \%$ as injectable probes of cellular metabolism. In vivo MR spectroscopic imaging of the metabolites of hyperpolarized contrast agents such as $\left[1-{ }^{13} \mathrm{C}\right]$ pyruvate and $\left[1-{ }^{13} \mathrm{C}\right.$-]lactate have been used to differentiate tissue undergoing anaerobic glycolysis, most notably associated with cancer and hypoxia (38-41).

This article reviews the current state of hyperpolarized MRI in the context of a mechanistic picture of RILI pathogenesis. Several important experimental hyperpolarized MRI approaches are presented, and results of anatomical and functional hyperpolarized ${ }^{129} \mathrm{Xe} \mathrm{MRI}$ of RILI are summarized, including ADC mapping, morphometry and gas exchange measurement using a whole-thorax model of RILI in the rat. Next, metabolic MRI studies using hyperpolarized $\left[1^{13} \mathrm{C}\right]$ pyruvate for early detection of RILI in a rat model are described. Finally, limitations and future directions of hyperpolarized MRI are presented, and extensions to clinical applications are discussed.

\section{Pathogenesis of RILI}

Following acute radiation damage, the inflammatory cascade associated with RILI (Fig. 1) consists of two main phases: (i) an early phase characterized by RP and (ii) a later phase characterized by tissue remodeling and fibrosis $(42,43)$, though one can occur without the other. The RP stage, typically lasting days to several weeks, is initiated by an overwhelming inflammatory response believed to be triggered by cytokines (e.g. interleukin 6, tumor necrosis factor alpha) released by activated resident leukocytes (i.e. macrophages), signaling migrating leukocytes (e.g. macrophages and neutrophils) to adhere to and penetrate the injured epithelial and endothelial layers. If injury to the alveolar epithelium is significant and/or unrepaired, chronic fibrosis will result (months). This can lead to progressive lung function loss and ultimate organ failure, affecting about $50 \%$ of individuals with severe lung injury. The occurrence of RP is characterized by the onset of inflammation, which is highly dependent on the release of inflammatory cytokines (44). Immunohistochemical analysis of RP in animal models reveals underlying cellular changes including increases in alveolar macrophages, inflammatory cytokines and type II pneumocytes $(45,46)$. These changes are observed both within and outside the region of conformal RT $(47,48)$, and persist up to four weeks post irradiation in rats (49).

Detection of RILI and its severity in the RP stage, before irreversible fibrosis, could potentially alter the course of RT fractionation and/or initiate adjuvant therapy earlier to mitigate RILI and improve patient outcome. A number of microanatomical and functional changes accompanying RP may be useful targets 


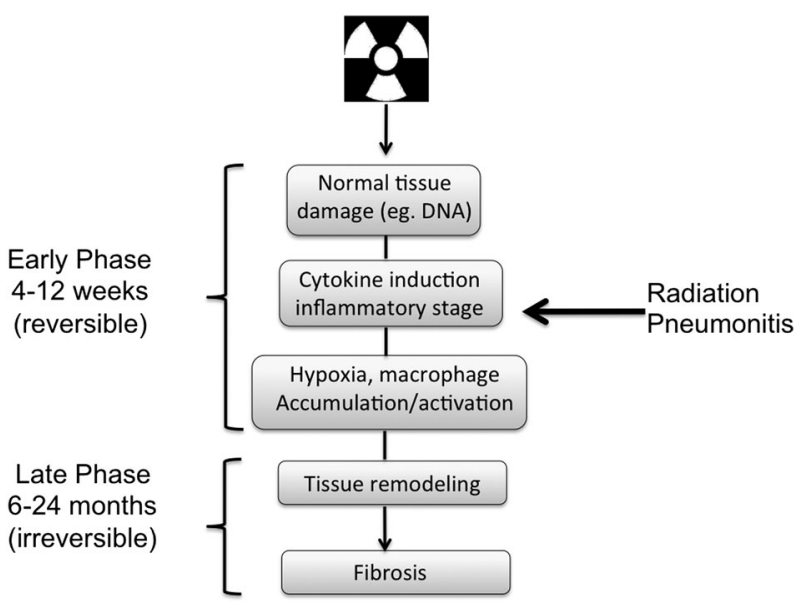

Figure 1. Generalized RILI time course. Following acute radiation damage, the injury consists of two distinct phases: (i) an early phase consisting of cytokine induction leading to inflammation and hypoxia (hours to weeks) and (ii) a later phase consisting of tissue remodeling and fibrosis (months). Hyperpolarized MRI potentially can be used detect the early phase, particularly RP (arrow), where the effects of RILI are most likely to be mitigated. (Figure adapted from Ghafoori et al. (8)).

for hyperpolarized MRI methods. The RP phase is marked by loss of alveolar function due to flooding (i.e. edema) from epithelial damage, thickening of alveolar and capillary walls and inactivation of surfactant leading to reductions in ventilation and perfusion, ultimately leading to hypoxia/ischemia, compromised gas exchange and reduced lung compliance (50). ADC of hyperpolarized ${ }^{129} \mathrm{Xe}$ MRI may be employed to detect the reduction of alveolar air space associated with RP, while measurement of the time for ${ }^{129} \mathrm{Xe}$ to diffuse through the alveolar wall can enable the detection of the thickening of alveolar walls due to RP.

From the metabolic standpoint, hypoxia in lung tissue plays a role in mediation of the inflammatory process in RP (51). Decreased arterial partial pressure of oxygen $\left(p_{\mathrm{a}} \mathrm{O}_{2}\right)$, an indicator of hypoxia (52), has been reported following RT $(53,4)$. Recent observations from lung cancer patients post irradiation suggest a strong correlation between dynamic changes in serum markers (i.e. cluster of differentiation 35) and onset of RP (54), and between the amount of exhaled nitric oxide (NO) and onset of RP (55). Hypoxia during RP is expected to increase the level of anaerobic glycolysis to meet the constant energy needs of the lung tissue, which in turn leads to a higher level of lactate. Therefore, MRI using hyperpolarized $\left[1-{ }^{13} \mathrm{C}\right]$ pyruvate and $\left[1-{ }^{13} \mathrm{C}\right]$ lactate may be particularly sensitive to RP.

\section{APPLICATION OF HYPERPOLARIZED MRI TO RILI}

\section{Hyperpolarized noble gases for anatomical and functional MRI of RILI}

Hyperpolarized ${ }^{3} \mathrm{He}$ gas has been used for studies of RILI, in both clinical subjects and animal models. These include identification of ventilation defect progression, stasis and decline correlated with the presence of RILI measured longitudinally $(1,56,52,57)$ as well as approaches to register ${ }^{3} \mathrm{He}$ images with $\mathrm{CT}$ images to enable computation of RT plans for functional lung avoidance $(58,59)$. However, the presumption that ventilation defects reflect functional deficits (i.e. non-ventilated lung) due to RILI may not be strictly true in the presence of tumor and other airway obstruction, commonly found in COPD, a co-morbidity of lung cancer. In this regard, mapping of ADC may be particularly useful for identifying microstructural changes associated with RP in ventilated lung, as alveolar gas space decreases due to inflammation are opposite to the alveolar enlargement expected in emphysema, a common component of COPD. Decreases in ${ }^{3} \mathrm{He} A D C$ corresponding to regions of fibrosis related to radiation exposure have been reported in a rat model of RILI consisting of fractionated delivery of $40 \mathrm{~Gy}$ to the right lung (33). ${ }^{3} \mathrm{He}$ ADC mapping has also been conducted in lung cancer patient populations (1).

While the scarcity of ${ }^{3} \mathrm{He}$ will likely limit its wide-spread clinical application, ${ }^{129} \mathrm{Xe}$ is more abundant and less expensive and has the additional advantage of relatively high tissue solubility permitting mapping of gas exchange and perfusion. Although ${ }^{129} \mathrm{Xe}$ development has lagged in comparison to ${ }^{3} \mathrm{He}$, recent technical advances significantly improving the achievable levels of polarization in clinically relevant quantities $(60,61)$ have renewed interest in ${ }^{129} \mathrm{Xe}$ for lung imaging, specifically mapping of microanatomical changes using ADC, as well as imaging of gas exchange. With a self-diffusion coefficient approximately onetenth that of ${ }^{3} \mathrm{He},{ }^{129} \mathrm{Xe}$ gas provides diffusion length scales that better match the alveolar size $(\sim 100-300 \mu \mathrm{m})$ at the diffusion times (several milliseconds) typical of clinical MRI systems, and therefore may be preferable for measurement of alveolar damage due to RILI.

Microanatomical MRI of RP: ${ }^{129}$ Xe ADC mapping and morphometry

In our laboratory, we have developed a model of RP using thoracic irradiation of the rat lung. This animal model permits the design of cohort studies to look at the longitudinal effects of RP in a controlled setting particularly the early RP stage (typically at 2 weeks and 6 weeks post-irradiation), which is not generally possible in a human population, where RP can remain undetectable using standard techniques (described above). In our set-up, Sprague Dawley rats receive thoracic irradiation using a ${ }^{60} \mathrm{Co}$ source with an average dose rate of $2 \mathrm{~Gy} / \mathrm{min}$ for a total dose of $14 \mathrm{~Gy}$ (62). Age-matched Sprague Dawley rats that are not exposed to radiation serve as healthy controls. Following imaging, the lungs are fixed by intratracheal infusion of $8 \mathrm{~mL}$ of $10 \%$ neutral-buffered formalin and allowed a fixation period of at least $24 \mathrm{~h}$. The fixed lung specimens are then embedded in paraffin wax, cut into $5 \mu \mathrm{m}$ thick tissue sections and stained with hematoxylin and eosin. Figure 2 shows representative sections of a healthy rat lung and a rat lung 2 weeks post irradiation.

For ADC mapping, a two-dimensional diffusion-weighted fast gradient echo is typically employed (35) with sufficient diffusion time (a few milliseconds) to ensure diffusion lengths are matched to alveolar dimensions. A single diffusion gradient sensitization (i.e. $b$-value) is chosen to achieve adequate contrast (typically $10-20 \mathrm{~s} / \mathrm{cm}^{2}$ ); however, a range of $b$-values can also be applied to investigate diffusional anisotropy. Diffusion in the terminal airways of the lung can be described by two anisotropic diffusion coefficients: (i) the longitudinal diffusion coefficient $\left(D_{\mathrm{L}}\right)$, describing diffusion along the length of the airway, and (ii) the transverse diffusion coefficient $\left(D_{\mathrm{T}}\right)$, describing diffusion perpendicular to the length of the airway (63). Figure 3(a), (b) shows transverse and longitudinal views respectively of the theoretical cylinder model, where the 
(a)

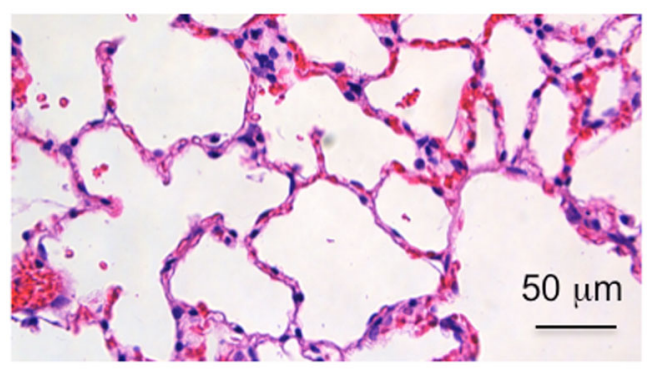

(b)

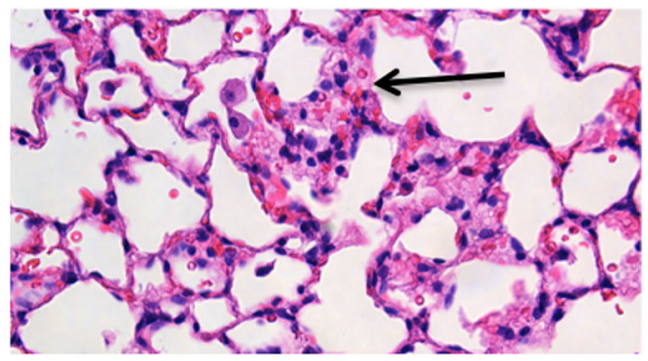

Figure 2. Representative histological sections $(40 x)$ obtained from (a) healthy rat lung and (b) rat lung two weeks following $14 \mathrm{~Gy}$ irradiation. Note the significant thickening of the alveolar walls in (b) compared with (a) due to inflammation associated with RP (shown by arrow). (a)

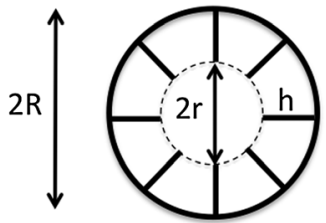

(b)

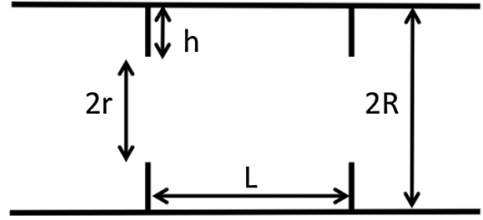

Figure 3. Cylinder model of the terminal airway seen in the (a) transverse view and (b) longitudinal view showing the outer airway radius $(R)$, inner radius $(r)$, alveolar sleeve depth $(h)$ and alveolar size $(L)$. The model is used to extract pixel-wise morphological parameters from maps of anisotropic diffusion coefficients. terminal airway is represented by a cylinder (inner radius $r$, outer radius $R$ ) containing alveoli of size $L$ and sleeve depth $h$. Morphometric maps of the terminal airway can be computed from $D_{\mathrm{L}}$ and $D_{\mathrm{T}}$ maps using the phenomenological model of Sukstanskii and Yablonskiy (63). Figure 4 shows 2D coronal projection xenon density images along with the corresponding morphometric maps for $r$ and $h$ computed using the cylinder model (64), for both a representative healthy rat (Fig. 4(a)) and a rat two weeks post irradiation (Fig. 4(b)). In Figure 4(a), (b), the major airways were removed from the diffusion maps prior to morphometric analysis. The morphometric maps show significant decreases in $r$ and increases in $h$ for the irradiated rat compared with the healthy rat consistent with inflammation, whereas little difference is seen in the density-weighted image. This suggests that underlying RP changes due to inflammation are not affecting ventilation at this relatively early stage of RILI. Based on a cohort of healthy $(n=3)$ and a cohort of irradiated rats $(n=3)$, the mean $r$ values decreased from $136( \pm 19) \mu \mathrm{m}$ to $102( \pm 30) \mu \mathrm{m}(p=0.029)$ respectively and the mean $h$ values increased from $46( \pm 17) \mu \mathrm{m}$ to 71 $( \pm 27) \mu \mathrm{m}(p=0.008)$ respectively.

Functional MRI of RILI: dissolved-phase ${ }^{129}$ Xe MRI and measurement of gas exchange

${ }^{129} \mathrm{Xe}$ gas, equilibrating in the lungs, consists of a gas resonance as well as several distinct dissolved-phase resonances, corresponding to various tissue compartments including lung parenchyma and red blood cells (RBCs), among others (65). Spectroscopy of ${ }^{129} \mathrm{Xe}$ dissolved in lung parenchymal tissue and RBCs was first reported by Sakai et al. in rats (66) and Mugler et al. (67) in humans. The application of ${ }^{129}$ Xe dissolved-phase imaging techniques to the detection of RILI was first reported by Driehuys et al. (68), where reductions in RBC image intensities were demonstrated in a rat model three months post-irradiation using a single dose of $28 \mathrm{~Gy}$. The effect of xenon transfer between the gas phase and the various dissolved-phase compartments is important for interpreting dissolved-phase image intensity and can also provide quantitative information concerning gas-exchange impairment with RILI. (a)

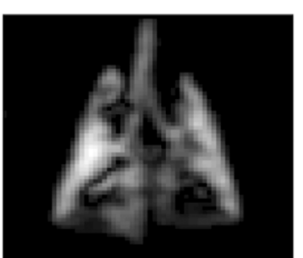

(b)

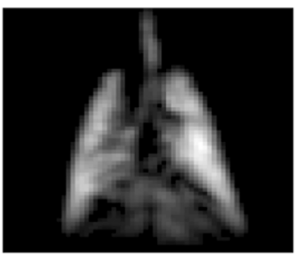

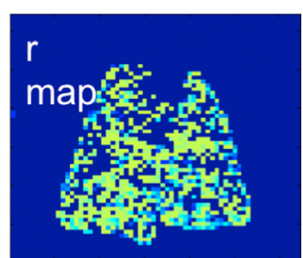

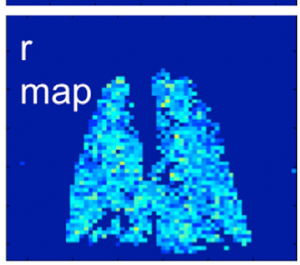

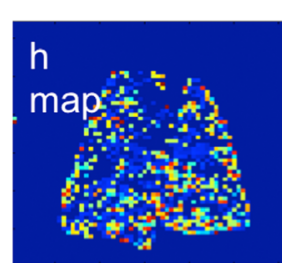

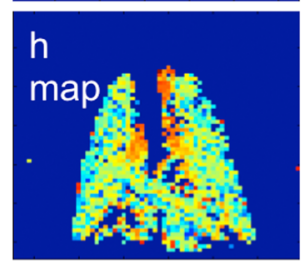

250

200

150

100

50

0

$$
\mu \mathrm{m}
$$

Figure 4. Representative coronal ${ }^{129}$ Xe lung images and corresponding morphometry $(r, h)$ maps for (a) healthy rat lungs and (b) rat lungs two weeks following irradiation. Note that the ${ }^{129}$ Xe images show relatively little difference between (a) and (b), whereas the morphometry is significantly different. 
Several dynamic ${ }^{129}$ Xe spectroscopic approaches have been developed, in both humans and animals, based on xenon transfer between the gas phase and the dissolved phases, including chemically selective saturation recovery (CSSR) (69), xenon transfer contrast (XTC) (70), xenon alveolar capillary transfer (32), multiple exchange time xenon polarization transfer contrast (71) and, more recently, the model of xenon transfer exchange $(72,73)$. The application of ${ }^{129}$ Xe XTC imaging techniques to the detection of RILI was first reported by Ruppert et al. (74), where reductions in XTC signal were reported at four months post irradiation in a rabbit model of RILI involving three fractions of $20 \mathrm{~Gy}$ delivered to the right lung. In that work, it was suggested that this was a reflection of reduced gas exchange, consistent with blood vessel damage confirmed histologically.

In contrast to XTC, CSSR resolves the tissue and RBC dissolved phases directly as a function of a characteristic delay time $\tau$, allowing measurement of compartment-specific gas transfer time constants $T_{\text {Tr_tissue }}$ and $T_{\mathrm{Tr} \_ \text {RBC }}$, which may each be differentially sensitive to gas exchange and perfusion. Figure 5 shows a representative set of CSSR data we have obtained from the lungs of a healthy rat for both the tissue and the RBC compartments as well as the gas-phase resonance for comparison. Theoretical models of xenon exchange measured with CSSR have been explored in humans (75) and rat models of inflammation using lipopolysaccharide (24) and bleomycin (32). Xenon diffusing capacity analogous to the diffusing capacity of carbon monoxide can also be measured using CSSR, and has been explored for assessment of inflammation due to fungal infection (25).

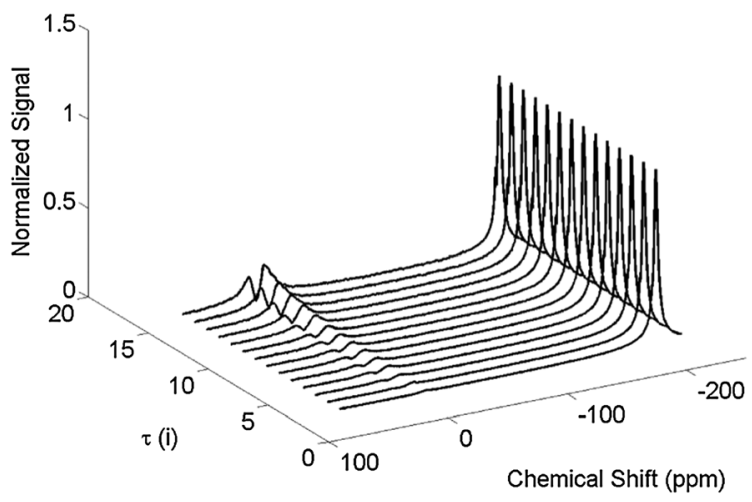

Figure 5. Hyperpolarized CSSR spectra as a function of $\tau$ from a healthy rat lung showing gas peaks (right) as well as two dissolved-phase peaks (left) corresponding to the RBC and lung tissue compartments respectively.
Our laboratory has used dynamic CSSR spectroscopy to investigate RP in the ${ }^{60} \mathrm{Co}$ irradiation rat model described above, at two and six weeks post-irradiation (76). Figure 6 shows representative CSSR curves obtained from a representative healthy rat (Fig. 6(a)) and a two-week irradiated rat (Fig. 6(b)) (76). The solid curves are the best fit to the data using the theoretical model of Mansson et al. (24), yielding whole-lung estimates of $T_{\mathrm{Tr} \text { tissue }}$ and $T_{\mathrm{Tr}_{\text {RBCC}} \text {. Figure }} 7(\mathrm{a})$ presents the mean transfer times obtained for the age-matched healthy cohort as well as the irradiated cohorts at two weeks and six weeks post irradiation. Post hoc $t$-tests revealed that $T_{\operatorname{Tr} \text { tissue }}$ in the twoweek group was statistically significantly elevated compared with the healthy and six-week groups $(p<0.05)$ (76). This increase in transfer time was attributed to gas exchange reductions caused by alveolar gas barrier thickening, a consequence of inflammation in RP. These increases in gas transfer times were also shown to be consistent with $p_{\mathrm{a}} \mathrm{O}_{2}$ reductions (Fig. 7(b)) and alveolar gas barrier thickening (Fig. 2(b)) and/or surface to volume ratio reductions measured using blood gas analysis and histology respectively in other cohorts similarly irradiated (76). It is likely that such whole-lung estimates of gas exchange will benefit in the future from the ability to spatially resolve changes that may be occurring regionally in the lung.

\section{Hyperpolarized ${ }^{13} \mathrm{C}$ for metabolic MRI of RILI}

To our knowledge, the first use of hyperpolarized ${ }^{13} \mathrm{C}$ in the lung was undertaken by Ishii et al., where ${ }^{13} \mathrm{C}$-enriched hydroxyethylpropionate was used to image pulmonary blood flow in the lungs of a healthy pig (77). For metabolic imaging, the pyruvate molecule enriched with ${ }^{13} \mathrm{C}$ at the $\mathrm{C}-1$ position can be polarized to a high degree and the conversions of $\left[1-{ }^{13} \mathrm{C}\right]$ pyruvate to its metabolic products, $\left[1-{ }^{13} \mathrm{C}\right]$ lactate, ${ }^{13} \mathrm{C}$-bicarbonate and $\left[1-{ }^{13} \mathrm{C}\right]$ alanine, have been observed in vivo for detection of cancer in animal models $(40,78)$, and humans (79). Specifically, the ratio of $\left[1-{ }^{13} \mathrm{C}\right]$ lactate signal to $\left[1-{ }^{13} \mathrm{C}\right]$ pyruvate signal (lac/pyr) has been shown to reflect the presence of anaerobic glycolysis in tumors, a surrogate for hypoxia (79). $\left[1-{ }^{13} \mathrm{C}\right]$ pyruvate has also been used to detect reductions in reactive oxygen species following irradiation of anaplastic thyroid carcinoma xenografts in mice (80).

Although the application of hyperpolarized $\left[1-{ }^{13} \mathrm{C}\right]$ pyruvate imaging to the lung presents significant challenges mainly due to the low tissue concentrations afforded by intravenous injection, $\left[1-{ }^{13} \mathrm{C}\right]$ lactate labeling following injection of $\left[1-{ }^{13} \mathrm{C}\right] \mathrm{py}$ ruvate has been used to investigate lung ischemia in the isolated perfused rat lung ex vivo (81). The ex vivo perfused organ (a) Healthy rat lung

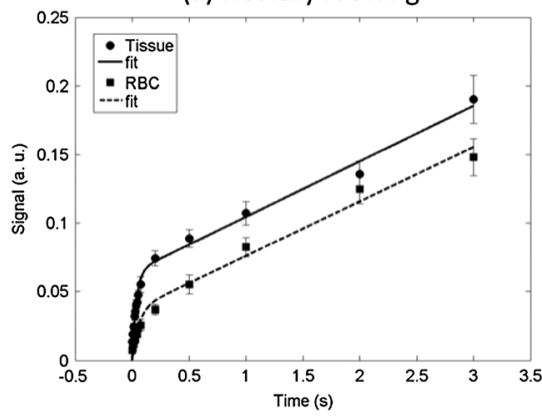

(b) Rat lung 2 weeks post-irradiation

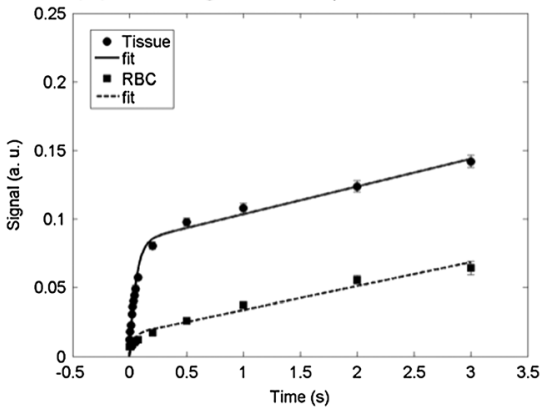

Figure 6. Representative $\operatorname{CSSR}{ }^{129}$ Xe signals as a function of $\tau$ for lung tissue (199 ppm) and RBCs (212 ppm) in (a) a healthy rat and (b) an irradiated rat two weeks post irradiation. The points represent the measured data and the lines represent the best fit to the data based on the model of Mansson et al. (24). 
(a)

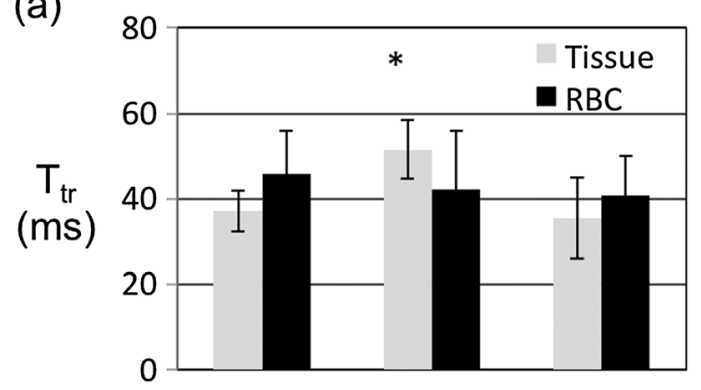

(b)

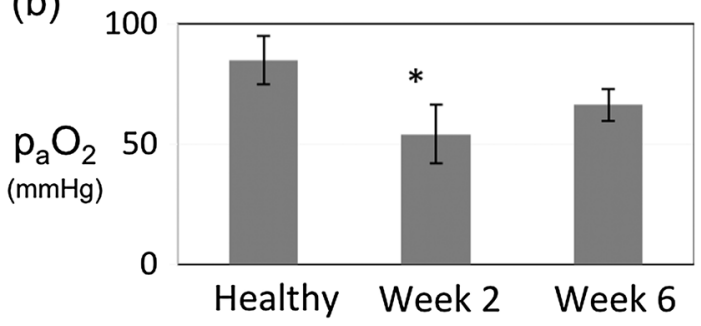

Figure 7. (a) Mean $T_{\mathrm{Tr}}$ values for lung tissue and RBCs measured in a healthy rat cohort and an irradiated rat cohort two and six weeks following irradiation. (b) Corresponding mean arterial blood oxygen partial pressure measured in similar cohorts. A statistically significant increase in $\left.T_{\mathrm{Tr}}{ }^{*} p<0.05\right)$ was seen for lung tissue in the irradiated cohort at two weeks compared with the healthy cohort, consistent with arterial blood oxygenation changes.

approach is a useful model system to investigate the time course of hyperpolarized $\left[1-{ }^{13} \mathrm{C}\right]$ pyruvate and its products in the lung with the opportunity to manipulate the metabolic environment (e.g. hypoxia) in a controlled way. In that work, a several-fold increase in lactate labeling was observed during conditions of ischemia compared with the base-line (i.e. normoxic) state. This increase in lactate labeling was seen to revert to baseline upon reperfusion and was consistent with changes in high-energy phosphate metabolism measured using ${ }^{31} \mathrm{P}$ NMR (81).

The first in vivo hyperpolarized ${ }^{13} \mathrm{C}$-pyruvate investigation of the lung, and of RILI, was reported by Thind et al. (62). In that work, lac/pyr was observed to increase by $110 \%(p<0.01), 57 \%$ $(p<0.02)$ and $107 \%(p<0.01)$ respectively in the entire thorax, lung and heart tissues of rats two weeks post whole-thorax irradiation (14Gy, as described above) compared with healthy age-matched rats. This was consistent with RP confirmed using cell micrographs of bronchioalveolar lavage specimens and decreases in arterial oxygen partial pressure $\left(p_{a} \mathrm{O}_{2}\right)$, indicative of hypoxia. This was not seen in tissues outside the field of irradiation (i.e. kidneys), nor were changes reported in blood lactate levels, confirming the injury was confined to the thorax (62).

More recently, our group has used hyperpolarized $\left[1-{ }^{13} \mathrm{C}\right]$ pyruvate to investigate the regional and longitudinal metabolic effects of RILI using an in vivo model of RILI involving conformal irradiation of the rat (82). In this study, the right medial lobe of the lungs of 12 Sprague Dawley rats were irradiated in two fractions with a total dose of $18.5 \mathrm{~Gy}$ using a modified $\mu \mathrm{CT} / \mathrm{RT}$ system (83). Fluoroscopy was employed to set the irradiation field to completely shield the beating heart. ${ }^{13} \mathrm{C}$-labelled pyruvic acid was hyperpolarized using a commercial DNP system (HyperSense, Oxford Instruments) and chemical shift imaging (CSI) performed at 3T (GEHC Discovery MR750, Waukesha, WI) following tail vein injection (62). Regional lactate and pyruvate data were acquired from three irradiated and three age-matched healthy rats at 5, 10,15 and 25 days post-RT. Arterial blood was collected from each animal prior to the $\left[1-{ }^{13} \mathrm{C}\right]$ pyruvate injection and was analyzed for blood lactate concentration and arterial oxygen concentration $\left(p_{\mathrm{a}} \mathrm{O}_{2}\right)$. Macrophage count was computed from histology of all rat lungs. Figure 8 shows the slab localized in the rat as a transverse plane encoded with CSI voxels overlaid on a standard proton $T_{1}$-weighted image. Four voxels were selected from the left lung, right lung and heart regions from each animal and were analyzed for lac/pyr. Arterial blood was collected from each animal prior to the pyruvate injection and was analyzed for blood lactate concentration and arterial oxygen concentration $\left(p_{\mathrm{a}} \mathrm{O}_{2}\right)$. Following imaging, the rat lungs were removed, fixed, sectioned and stained for histological analysis.

Figure 9 shows the corresponding lac/pyr values for the right lung and heart regions shown in Figure 8 at all time points. Statistically significant increases in lac/pyr $(p<0.05)$ in the irradiated (right) lung were observed compared with healthy rats at days 5, 10, 15 and 25-post irradiation (82). No increase in lac/pyr was observed in the hearts of the irradiated cohort compared with the hearts of the healthy cohorts. Neither blood lactate concentration nor $p_{\mathrm{a}} \mathrm{O}_{2}$ showed a significant change between the irradiated and the healthy cohorts. Macrophage counts in both right and left lung were elevated for the irradiated cohort compared with the healthy cohort (82), consistent with the RP inflammatory phase of early RILI (84).

Interestingly, a significant increase in lac/pyr was observed in both the right and left lungs of the irradiated cohort compared with the healthy cohort for all time points. Macrophage counts from the right and left lungs of both the healthy rats and the irradiated rats appeared to be highly correlated to the lac/pyr values at all time points, with a Spearman correlation coefficient of $0.86(p<0.01)$ for the right lung and $0.85(p<0.01)$ for the left lung (Fig. 10). No statistically significant changes were observed in lac/pyr in the heart or in blood lactate levels or $p_{\mathrm{a}} \mathrm{O}_{2}$ between healthy and irradiated animals at any time point. Furthermore,

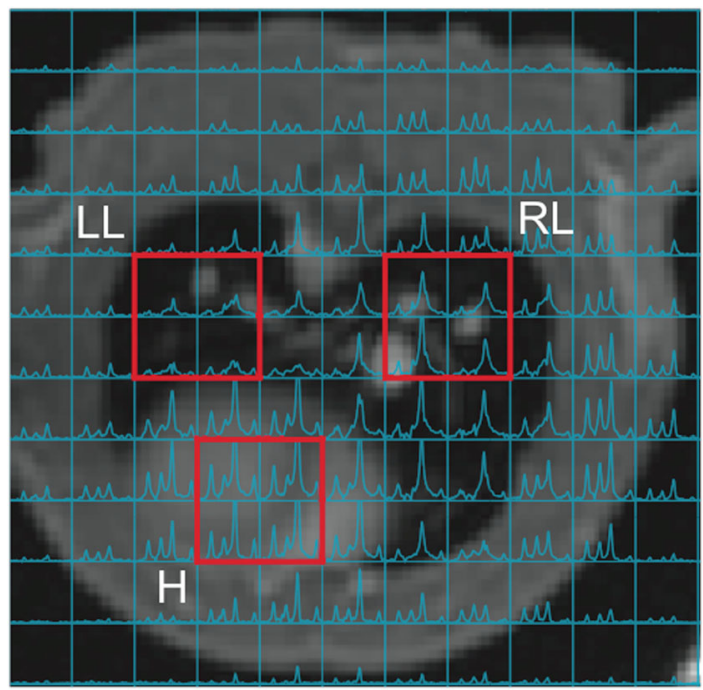

Figure 8. ${ }^{13} \mathrm{C}$ MR spectroscopic imaging voxels overlaid on $T_{1}$-weighted ${ }^{1} \mathrm{H}$ axial image. The lung boundary is clearly visualized as a signal void. ${ }^{13} \mathrm{C} \mathrm{lac} /$ pyr measurements were taken in 12 voxels, four each from the left lung (LL), right lung $(\mathrm{RL})$ and heart $(\mathrm{H})$ regions as indicated. Figure reprinted from Reference 86 with permission from Elsevier. 


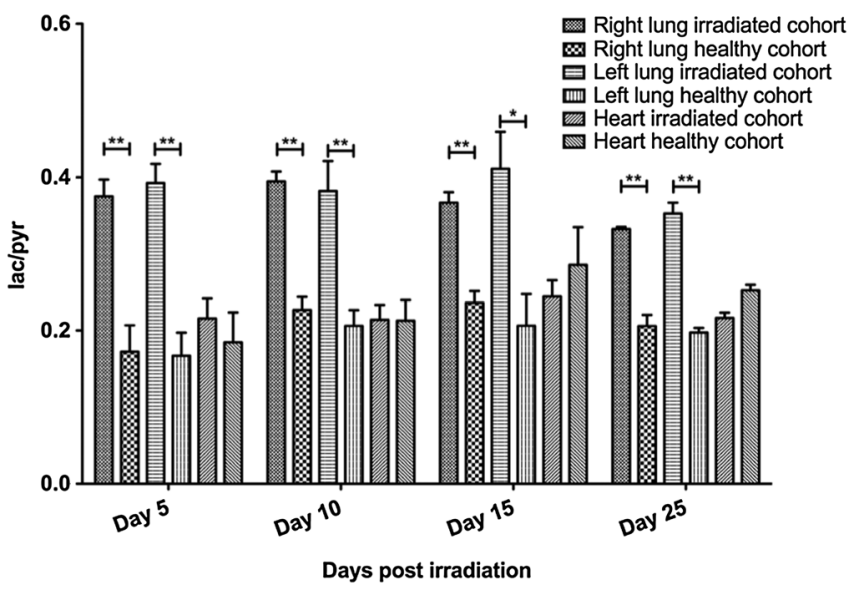

Figure 9. Mean ( \pm 1 standard deviation) lac/pyr measured for the right lung, left lung and heart regions in the healthy and irradiated cohorts at four time points $(5,10,15$ and 25 days) following irradiation. Statistically significant increases in lac/pyr $\left({ }^{* *} p<0.01,{ }^{*} p<0.05\right)$ are apparent in the right lung and left lung of the irradiated cohort compared with the right lung and left lung of the healthy cohort or the heart region at all time points post irradiation. Figure reprinted from Reference 86 with permission from Elsevier.

no histological evidence of inflammation was observed in the heart at days 10 and 15 post RT. The absence of changes in blood lactate and $p_{\mathrm{a}} \mathrm{O}_{2}$ levels as well as the absence of changes in lac/pyr and histology in the heart confirms that the response to injury was confined to the lung. The reduction in lac/pyr at day 25 suggests that inflammation may have started to subside at this time point (82).

\section{DISCUSSION AND FUTURE DIRECTIONS}

RILI is an important limiting factor in the RT treatment of thoracic cancers, most notably NSCLC, responsible for $80 \%$ of lung cancer. Strategies to mitigate RILI, which subsequently results in irreversible fibrosis, may benefit from early detection of RP, where the effects are most readily treated. MRI with hyperpolarized nuclei, specifically following inhalation of ${ }^{129} \mathrm{Xe}$ and injection of $\left[1-{ }^{13} \mathrm{C}\right]$ pyruvate, may offer a useful approach for detection of RP. To the extent that these hyperpolarized nuclei can be delivered to the injured portions of the lung, these approaches can offer valuable insight into the microanatomical, functional and metabolic changes accompanying RILI. Irradiation of animal (i.e. rodent) lungs, both whole-thorax as well as conformal delivery, can be useful for imaging RILI in a controlled fashion, particularly to study longitudinal effects and correlate with histological changes.

MRI of the apparent diffusion of hyperpolarized noble gases is a powerful tool for quantifying regional microanatomical changes associated with RILI. For the diffusion times and gas mixtures typically used in hyperpolarized ${ }^{129} \mathrm{Xe} \mathrm{MRI,} \mathrm{the} \mathrm{diffusion}$ lengths are ideally suited for probing changes in the morphometry of the terminal airways and alveoli associated with RILI. In particular, alveolar size and internal radius of the terminal airway are observed to decrease and alveolar sleeve depth is observed to increase due to inflammation associated with RP. These changes are qualitatively consistent with histology and will be reported in detail in a future publication. The use of morphometry to investigate longitudinal changes, especially from conformal irradiation and fractionated delivery similar to that used clinically, and correlation with quantitative histology, will likely be fruitful areas of future research. MRI morphometry is also expected to benefit from emerging 3D histology approaches in order to validate microanatomical changes which are inherently $3 \mathrm{D}$ in nature.

The dual capability of hyperpolarized ${ }^{129} \mathrm{Xe}$ to probe functional as well as anatomical changes associated with RILI is expected to be particularly beneficial for detection of RP, since functional deficits (e.g. gas exchange and perfusion) are expected to precede morphological changes. The ability to resolve ${ }^{129} \mathrm{Xe}$ dissolved in both the lung tissue compartment and blood compartment (i.e. RBCs) and measure the relative dynamics of the ${ }^{129} \mathrm{Xe}$ signal from these compartments, particularly following selective RF pulse strategies (e.g. CSSR), allows measurement of gas exchange reductions associated with RP inflammation as early as two weeks. The use of the ${ }^{129} \mathrm{Xe}$ RBC signal as an indication of blood vessel destruction expected to accompany early radiation damage could provide valuable mechanistic insight. Figure 6 suggests that decreases in the ratio of ${ }^{129} \mathrm{Xe}$ signal from the RBC phase relative to the tissue phase may occur, possibly associated with gas exchange impairment and/or loss of vasculature. Further work is needed in order to delineate the interplay of these mechanistic processes and this will likely be aided by the use of more sophisticated animal experiments, higher nuclear polarizations and spectroscopic imaging techniques (e.g. Dixon-based techniques). For example, the effects of total dose, conformation, dose rate and fractionation
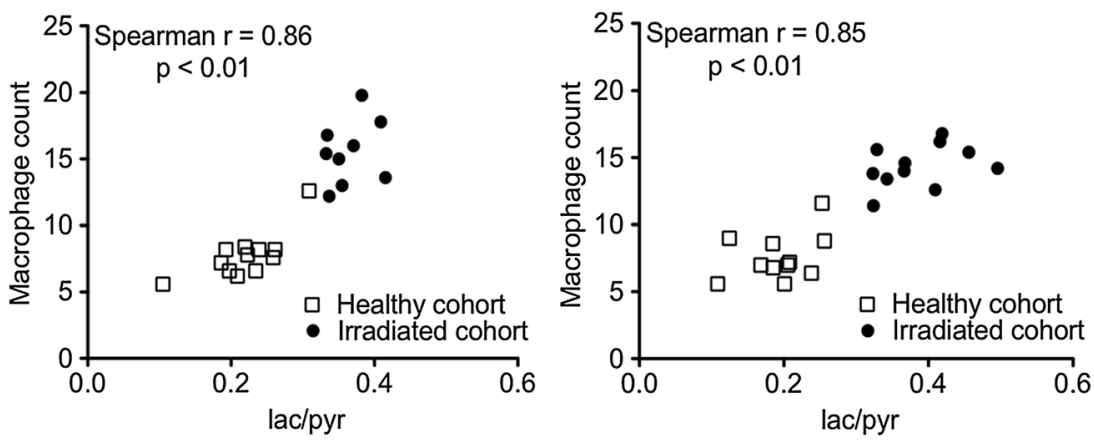

Figure 10. Scatter plots of lac/pyr versus macrophage count obtained by histology in right lung (on left) and left lung (on right) for the healthy rat cohort and the irradiated rat cohort, showing strong correlation in both the right lung $(r=0.86, p<0.01)$ and the left lung $(r=0.85, p<0.01)$ respectively. Figure reprinted from Reference 86 with permission from Elsevier. 
scheme could be studied. The data could be collected for a longer time span (e.g. zero days to 20 weeks post irradiation procedure) to understand the effects of the underlying injury on gas exchange.

Animal studies should also advance our understanding of the metabolic changes associated with RILI, specifically the origin of the $\left[1-{ }^{13} \mathrm{C}\right]$ lactate changes. This would include correlation of lac/pyr ratio and identification of the type of proliferating leukocyte. Comparison of lac/pyr data with histology following hypoxia staining as well as leukocyte counting could help decode the origin of lac/pyr changes in RP. Additional studies could be performed to profile the inflammatory cytokines, other leukocytes (e.g. neutrophils), type II pneumocytes, endothelial cells and fibroblasts in a similar manner to test the relationship between lac/pyr and the evolution of these physiological parameters as a function of time and following administration of radioprotector chemical species such as superoxide dismutase post-irradiation (49). The role of the contralateral lung in RILI response is also worthy of further investigation.

Though the application of hyperpolarized MRI is well developed in animal models, particularly $\left[1-{ }^{13} \mathrm{C}\right]$ pyruvate, clinical studies are lagging mainly due to the limited output and availability of this technology. This is expected to change with the emergence of turn-key polarizers capable of providing the necessary volumes, polarizations and quality suitable for human use. The clinical translation of these methods is unclear, but integration of hyperpolarized MRI into the therapy plan would likely be most useful prior to and within the first few weeks of RT delivery. Detection of early RP using hyperpolarized $\left[1-{ }^{13} \mathrm{C}\right] \mathrm{py}$ ruvate $\mathrm{MRI}$ could allow monitoring of ongoing radiation therapy of breast cancer, lung cancer and other thoracic cancers that may be susceptible to RILI. The information could be used as feedback for modification of the radiation therapy (or chemotherapy) plan or to determine whether anti-inflammatory drugs would help (e.g. corticosteroids). Since every patient may have a slightly different physiological make-up, $\left[1-{ }^{13} \mathrm{C}\right]$ pyruvate MRI could assist with personalized treatment, where the metabolism of each patient could be recorded and used in the ongoing therapeutic intervention. The non-ionizing nature of MRI also permits repeated scans for continuous monitoring of a patient, which may not be possible with PET or CT. Continuous monitoring may be important to track the evolution of both the tumor response and RP in cancer patients. While onset of RP leads to higher lac/pyr post radiation therapy in the non-cancerous injured lung, lung cancer cells may begin to demonstrate lower lac/pyr post therapeutic intervention, as demonstrated in the literature with other cancer cell lines (85). In addition, hyperpolarized ${ }^{13} \mathrm{C}$-bicarbonate might also be useful to map $\mathrm{pH}$ of tumors undergoing radiation therapy, as $\mathrm{pH}$ plays a vital role in tumor progression and therapy (86).

In summary, hyperpolarized MRI techniques, most notably ${ }^{129} \mathrm{Xe}$ gas and $\left[1-{ }^{13} \mathrm{C}\right]$ pyruvate, are very promising approaches for detection of anatomical, functional and metabolic changes associated with RILI. Early and regional detection of RP associated with RILI using these emerging imaging techniques may play a significant role in the personalization of ongoing RT and adjuvant therapy, thereby improving outcomes.

\section{Acknowledgements}

The authors wish to acknowledge the following sources of funding: Canadian Institutes for Health Research (operating grant MOP-123431), Ontario Research Fund (Ontario Preclinical
Imaging Consortium), Ontario Institute for Cancer Research and the Natural Sciences and Engineering Research Council. Kundan Thind was supported by studentships from the Canadian Institutes for Health Research, the Natural Sciences and Engineering Research Council and an Ontario Graduate Scholarship. The authors would also like to thank Adam Farag, Patrick Lai, Patrick Lim, Paula Pflugfelder and Zack Zytner for assistance with MRI experiments and data analysis. Special thanks to Dr lan Welch and the Foster laboratory for their assistance with histology and Drs Richard Hill and Andrew Hope for their help with the rat irradiation model of RILI.

\section{REFERENCES}

1. Mathew L, Vandyk J, Etemad-Rezai R, Rodrigues G, Parraga G. Hyperpolarized ${ }^{3} \mathrm{He}$ pulmonary functional magnetic resonance imaging prior to radiation therapy. Med. Phys. 2012; 39: 4284-4290.

2. Marks LB, Yu X, Vujaskovic Z, Small W, Jr, Folz R, Anscher MS. Radiation-induced lung injury. Semin. Radiat. Oncol. 2003; 13: 333-345.

3. Gross NJ. The pathogenesis of radiation-induced lung damage. Lung 1981; 159: 115-125.

4. Emirgil C, Heinemann $\mathrm{H}$. Effects of irradiation of chest on pulmonary function in man. J. Appl. Physiol. 1961; 16: 331-338.

5. Siemann DW, Hill RP. Quantitative changes in the arterial blood gases of mice following localized irradiation of the lungs. Radiat. Res. 1983; 93: 560-566.

6. Robbins ME, Brunso-Bechtold JK, Peiffer AM, Tsien Cl, Bailey JE, Marks LB. Imaging radiation-induced normal tissue injury. Radiat. Res. 2012; 177: 449-466.

7. Movsas B, Raffin TA, Epstein AH, Link CJ, Jr. Pulmonary radiation injury. Chest 1997; 111: 1061-1076.

8. Ghafoori P, Marks LB, Vujaskovic Z, Kelsey CR. Radiation-induced lung injury. Assessment, management, and prevention. Oncology 2008; 22: 37-47; discussion 52-53.

9. Ikezoe J, Takashima S, Morimoto S, Kadowaki K, Takeuchi N, Yamamoto T, Nakanishi K, Isaza M, Arisawa J, Ikeda H. CT appearance of acute radiation-induced injury in the lung. Am. J. Roentgenol. 1988; 150: 765-770.

10. Evans ES, Hahn CA, Kocak Z, Zhou SM, Marks LB. The role of functional imaging in the diagnosis and management of late normal tissue injury. Semin. Radiat. Oncol. 2007; 17: 72-80.

11. Seppenwoolde Y, De Jaeger K, Boersma LJ, Belderbos JS, Lebesque JV. Regional differences in lung radiosensitivity after radiotherapy for non-small-cell lung cancer. Int. J. Radiat. Oncol. Biol. Phys. 2004; 60: 748-758.

12. Marks LB, Munley MT, Spencer DP, Sherouse GW, Bentel GC, Hoppenworth J, Chew M, Jaszczak RJ, Coleman RE, Prosnitz LR. Quantification of radiation-induced regional lung injury with perfusion imaging. Int. J. Radiat. Oncol. Biol. Phys. 1997; 38: 399.

13. Boersma LJ, Damen E, de Boer RW, Muller SH, Olmos RV, van Zandwijk N, Lebesque JV. Recovery of overall and local lung function loss 18 months after irradiation for malignant lymphoma. J. Clin. Oncol. 1996; 14: 1431-1441.

14. Theuws J, Seppenwoolde Y, Kwa SL, Boersma LJ, Damen EM, Baas P, Muller SH, Lebesque JV. Changes in local pulmonary injury up to 48 months after irradiation for lymphoma and breast cancer. Int. J. Radiat. Oncol. Biol. Phys. 2000; 47: 1201-1208.

15. Petersson J, Sanchez-Crespo A, Larsson SA, Mure M. Physiological imaging of the lung: single-photon-emission computed tomography (SPECT). J. Appl. Physiol. 2007; 102: 468-476.

16. McCurdy MR, Castillo R, Martinez J, Al Hallack MN, Lichter J, Zouain N, Guerrero T. $\left[{ }^{18} \mathrm{~F}\right]$-FDG uptake dose-response correlates with radiation pneumonitis in lung cancer patients. Radiother. Oncol. 2012; 104: 52-57.

17. Moon DH, Maddahi J, Silverman D, Glaspy JA, Phelps ME, Hoh CK. Accuracy of whole-body fluorine-18-FDG PET for the detection of recurrent or metastatic breast carcinoma. J. Nucl. Med. 1998; 39: 431-435.

18. Ishimori $T$, Saga $T$, Nagata $Y$, Nakamoto $Y$, Higashi $T$, Mamede $M$, Mukai T, Negoro Y, Aoki T, Hiraoka M. ${ }^{18}$ F-FDG and ${ }^{11} \mathrm{C}$-methionine PET for evaluation of treatment response of lung cancer after stereotactic radiotherapy. Ann. Nucl. Med. 2004; 18: 669-674. 
19. Hicks RJ, Mac Manus MP, Matthews JP, Hogg A, Binns D, Rischin D, Ball $\mathrm{DL}$, Peters $\sqcup$. Early FDG-PET imaging after radical radiotherapy for non small-cell lung cancer: Inflammatory changes in normal tissues correlate with tumor response and do not confound therapeutic response evaluation. Int. J. Radiat. Oncol. Biol. Phys. 2004; 60: 412-418.

20. Ogasawara N, Suga K, Karino Y, Matsunaga N. Perfusion characteristics of radiation-injured lung on Gd-DTPA-enhanced dynamic magnetic resonance imaging. Invest. Radiol. 2002; 37: 448-457.

21. Shioya S, Tsuji C, Kurita D, Katoh H, Tsuda M, Haida M, Kawana A, Ohta Y. Early damage to lung tissue after irradiation detected by the magnetic resonance T2 relaxation time. Radiat. Res. 1997; 148: 359-364.

22. Driehuys B, Cates GD, Miron E, Sauer K, Walter DK, Happer W. High volume production of laser-polarized 129Xe. Appl. Phys. Lett. 1996; 69: 1668-1670.

23. Santyr GE, Lam WW, Ouriadov A. Rapid and efficient mapping of regional ventilation in the rat lung using hyperpolarized $3 \mathrm{He}$ with Flip Angle Variation for Offset of RF and Relaxation (FAVOR). Magn. Reson. Med. 2008; 59: 1304-1310.

24. Mansson S, Wolber J, Driehuys B, Wollmer P, Golman K. Characterization of diffusing capacity and perfusion of the rat lung in a lipopolysaccaride disease model using hyperpolarized ${ }^{129} \mathrm{Xe}$. Magn. Reson. Med. 2003; 50: 1170-1179.

25. Abdeen N, Cross A, Cron G, White S, Rand T, Miller D, Santyr G. Measurement of xenon diffusing capacity in the rat lung by hyperpolarized ${ }^{129} \mathrm{Xe} \mathrm{MRI}$ and dynamic spectroscopy in a single breath-hold. Magn. Reson. Med. 2006; 56: 255-264.

26. Evans A, McCormack D, Ouriadov A, Etemad-Rezai R, Santyr G, Parraga G. Anatomical distribution of $3 \mathrm{He}$ apparent diffusion coefficients in severe chronic obstructive pulmonary disease. J. Magn. Reson. Imaging 2007; 26: 1537-1547.

27. Peces-Barba G, Ruiz-Cabello J, Cremillieux Y, Rodriguez I, Dupuich D, Callot V, Ortega M, Rubio Arbo ML, Cortijo M, Gonzalez-Mangado N. Helium-3 MRI diffusion coefficient: correlation to morphometry in a model of mild emphysema. Eur. Respir. J. 2003; 22: 14-19.

28. Woodhouse N, Wild JM, Paley MN, Fichele S, Said Z, Swift AJ, van Beek EJ. Combined helium-3/proton magnetic resonance imaging measurement of ventilated lung volumes in smokers compared to never-smokers. J. Magn. Reson. Imaging 2005; 21: 365-369.

29. de Lange EE, Altes TA, Patrie JT, Gaare JD, Knake JJ, Mugler JP 3rd, Platts-Mills TA. Evaluation of asthma with hyperpolarized helium-3 MRI: correlation with clinical severity and spirometry. Chest 2006; 130: 1055-1062.

30. McMahon CJ, Dodd JD, Hill C, Woodhouse N, Wild JM, Fichele S, Gallagher CG, Skehan SJ, van Beek EJ, Masterson JB. Hyperpolarized 3helium magnetic resonance ventilation imaging of the lung in cystic fibrosis: comparison with high resolution CT and spirometry. Eur. Radiol. 2006; 16: 2483-2490.

31. van Beek EJ, Hill C, Woodhouse N, Fichele S, Fleming S, Howe B, Bott $\mathrm{S}$, Wild JM, Taylor CJ. Assessment of lung disease in children with cystic fibrosis using hyperpolarized 3-Helium MRI: comparison with Shwachman score, Chrispin-Norman score and spirometry. Eur. Radiol. 2007; 17: 1018-1024.

32. Driehuys B, Cofer GP, Pollaro J, Mackel JB, Hedlund LW, Johnson GA. Imaging alveolar-capillary gas transfer using hyperpolarized ${ }^{129} \mathrm{Xe}$ MRI. Proc. Natl. Acad. Sci. U. S. A. 2006; 103: 18278-18283.

33. Ward ER, Hedlund LW, Kurylo WC, Wheeler CT, Cofer GP, Dewhirst MW, Marks LB, Vujaskovic Z. Proton and hyperpolarized helium magnetic resonance imaging of radiation-induced lung injury in rats. Int. J. Radiat. Oncol. Biol. Phys. 2004; 58: 1562-1569.

34. Couch MJ, Ouriadov A, Santyr GE. Regional ventilation mapping of the rat lung using hyperpolarized ${ }^{129}$ Xe magnetic resonance imaging. Magn. Reson. Med. 2012; 68: 1623-1631.

35. Xu X, Boudreau M, Ouriadov A, Santyr GE. Mapping of ${ }^{3} \mathrm{He}$ apparent diffusion coefficient anisotropy at sub-millisecond diffusion times in an elastase-instilled rat model of emphysema. Magn. Reson. Med. 2012; 67: 1146-1153.

36. Boudreau M, Xu X, Santyr GE. Measurement of 129Xe gas apparent diffusion coefficient anisotropy in an elastase-instilled rat model of emphysema. Magn. Reson. Med. 2013; 69: 211-220.

37. Ardenkjaer-Larsen JH, Fridlund B, Gram A, Hansson G, Hansson L, Lerche $M H$, Servin R, Thaning M, Golman K. Increase in signal-tonoise ratio of $>10,000$ times in liquid-state NMR. Proc. Natl. Acad. Sci. U. S. A. 2003; 100: 10158-10163.

38. Schroeder MA, Atherton HJ, Ball DR, Cole MA, Heather LC, Griffin JL, Clarke K, Radda GK, Tyler DJ. Real-time assessment of Krebs cycle metabolism using hyperpolarized ${ }^{13} \mathrm{C}$ magnetic resonance spectroscopy. FASEB J. 2009; 23: 2529-2538.

39. Kohler SJ, Yen Y, Wolber J, Chen AP, Albers MJ, Bok R, Zhang V, Tropp J, Nelson $S$, Vigneron DB, Kurhanewicz J, Hurd RE. In vivo ${ }^{13}$ carbon metabolic imaging at 3T with hyperpolarized ${ }^{13} \mathrm{C}-1$-pyruvate. Magn. Reson. Med. 2007; 58: 65-69.

40. Albers MJ, Bok R, Chen AP, Cunningham CH, Zierhut ML, Zhang VY, Kohler SJ, Tropp J, Hurd RE, Yen YF, Nelson SJ, Vigneron DB, Kurhanewicz J. Hyperpolarized ${ }^{13} \mathrm{C}$ lactate, pyruvate, and alanine: noninvasive biomarkers for prostate cancer detection and grading. Cancer Res. 2008; 68: 8607-8615.

41. Chen AP, Albers MJ, Cunningham $\mathrm{CH}$, Kohler SJ, Yen YF, Hurd RE, Tropp J, Bok R, Pauly JM, Nelson SJ, Kurhanewicz J, Vigneron DB. Hyperpolarized $\mathrm{C}-13$ spectroscopic imaging of the TRAMP mouse at 3T - initial experience. Magn. Reson. Med. 2007; 58: 1099-1106.

42. Bentzen SM. Preventing or reducing late side effects of radiation therapy: radiobiology meets molecular pathology. Nat. Rev. Cancer 2006; 6: 702-713.

43. Tsoutsou PG, Koukourakis MI. Radiation pneumonitis and fibrosis: mechanisms underlying its pathogenesis and implications for future research. Int. J. Radiat. Oncol. Biol. Phys. 2006; 66: 1281-1293.

44. Hill RP, Zaidi A, Mahmood J, Jelveh S. Investigations into the role of inflammation in normal tissue response to irradiation. Radiother. Oncol. 2011; 101: 73-79.

45. Johnston CJ, Piedboeuf B, Baggs R, Rubin P, Finkelstein JN. Differences in correlation of mRNA gene expression in mice sensitive and resistant to radiation-induced pulmonary fibrosis. Radiat. Res. 1995; 142: 197-203.

46. Rodemann HP, Bamberg M. Cellular basis of radiation-induced fibrosis. Radiother. Oncol. 1995; 35: 83-90.

47. Khan MA, Hill RP, Van Dyk J. Partial volume rat lung irradiation: an evaluation of early DNA damage. Int. J. Radiat. Oncol. Biol. Phys. 1998; 40: 467.

48. Khan MA, Van Dyk J, Yeung IW, Hill RP. Partial volume rat lung irradiation; assessment of early DNA damage in different lung regions and effect of radical scavengers. Radiother. Oncol. 2003; 66: 95-102.

49. Calveley VL, Khan MA, Yeung IW, Vandyk J, Hill RP. Partial volume rat lung irradiation: temporal fluctuations of in-field and out-of-field DNA damage and inflammatory cytokines following irradiation. Int. J. Radiat. Biol. 2005; 81: 887-899.

50. Ding K, Bayouth JE, Buatti JM, Christensen GE, Reinhardt JM. 4DCTbased measurement of changes in pulmonary function following a course of radiation therapy. Med. Phys. 2010; 37: 1261-1272.

51. Vujaskovic Z, Anscher MS, Feng Q, Rabbani ZN, Amin K, Samulski TS, Dwehirst MW, Haroon ZA. Radiation-induced hypoxia may prepetuate late normal tissue injury. Int. J. Radiat. Oncol. Biol. Phys. 2001; 50: 5.

52. Ireland RH, Din OS, Swinscoe JA, Woodhouse N, van Beek EJ, Wild JM, Hatton MQ. Detection of radiation-induced lung injury in non-small cell lung cancer patients using hyperpolarized helium-3 magnetic resonance imaging. Radiother. Oncol. 2010; 97: 244-248.

53. Dietmar Siemann RH. Quantitative changes in the arterial blood gases of mice following localized irradiation of the lungs. Radiat. Res. 1983, 93: 560-566.

54. Bai L, Zhao J, Yu H, Zhao N, Liu D, Zhong W, Zhao Y. The CD36 dynamic change after radiation therapy in lung cancer patients and its correlation with symptomatic radiation pneumonitis. Radiother. Oncol. 2013; 107: 389-391.

55. McCurdy MR, Wazni MW, Martinez J, McAleer MF, Guerrero T. Exhaled nitric oxide predicts radiation pneumonitis in esophageal and lung cancer patients receiving thoracic radiation. Radiother. Oncol. 2011; 101: 443-448.

56. Allen AM, Albert M, Caglar HB, Zygmanski P, Soto R, Killoran J, Sun Y. Can hyperpolarized helium MRI add to radiation planning and follow-up in lung cancer? J. Appl. Clin. Med. Phys. 2011; 12: 3357.

57. Mathew L, Gaede S, Wheatley A, Etemad-Rezai R, Rodrigues GB, Parraga G. Detection of longitudinal lung structural and functional changes after diagnosis of radiation-induced lung injury using hyperpolarized ${ }^{3} \mathrm{He}$ magnetic resonance imaging. Med. Phys. 2010; 37: 22-31.

58. Ireland RH, Bragg CM, McJury M, Woodhouse N, Fichele S, van Beek EJ, Wild JM, Hatton MQ. Feasibility of image registration and intensity-modulated radiotherapy planning with hyperpolarized helium-3 magnetic resonance imaging for non-small-cell lung cancer. Int. J. Radiat. Oncol. Biol. Phys. 2007; 68: 273-281.

59. Mathew L, Wheatley A, Castillo R, Castillo E, Rodrigues G, Guerrero T, Parraga G. Hyperpolarized ${ }^{3} \mathrm{He}$ magnetic resonance imaging: 
comparison with four-dimensional x-ray computed tomography imaging in lung cancer. Acad. Radiol. 2012; 19: 1546-1553.

60. Hersman FW, Ruset IC, Ketel S, Muradian I, Covrig SD, Distelbrink J, Porter W, Watt D, Ketel J, Brackett J, Hope A, Patz S. Large production system for hyperpolarized ${ }^{129} \mathrm{Xe}$ for human lung imaging studies. Acad. Radiol. 2008; 15: 683-692.

61. Nikolaou P, Coffey AM, Walkup LL, Gust BM, Whiting N, Newton H, Barcus S, Muradyan I, Dabaghyan M, Moroz GD, Rosen MS, Patz S, Barlow MJ, Chekmenev EY, Goodson BM. Near-unity nuclear polarization with an open-source ${ }^{129}$ Xe hyperpolarizer for NMR and MRI. Proc. Natl. Acad. Sci. U. S. A. 2013; 110: 14150-14155.

62. Thind $K$, Chen A, Friesen-Waldner L, Ouriadov A, Scholl TJ, Fox M, Wong E, Vandyk J, Hope A, Santyr G. Detection of radiationinduced lung injury using hyperpolarized ${ }^{13} \mathrm{C}$ magnetic resonance spectroscopy and imaging. Magn. Reson. Med. 2012; 70: 601-609.

63. Sukstanskii AL, Yablonskiy DA. Lung morphometry with hyperpolarized 129Xe: theoretical background. Magn. Reson. Med. 2012; 67: 856-866.

64. Ouriadov A, Farag A, Kirby M, McCormack DG, Parraga G, Santyr GE. Lung morphometry using hyperpolarized ${ }^{129}$ Xe apparent diffusion coefficient anisotropy in chronic obstructive pulmonary disease. Magn. Reson. Med. 2013; 70: 1699-1706.

65. Swanson SD, Rosen MS, Coulter KP, Welsh RC, Chupp TE. Distribution and dynamics of laser-polarized ${ }^{129} \mathrm{Xe}$ magnetization in vivo. Magn. Reson. Med. 1999; 42: 1137-1145.

66. Sakai K, Bilek AM, Oteiza E, Walsworth RL, Balamore D, Jolesz FA, Albert MS. Temporal dynamics of hyperpolarized ${ }^{129}$ Xe resonances in living rats. J. Magn. Reson. B 1996; 111: 300-304.

67. Mugler JP 3rd, Driehuys B, Brookeman JR, Cates GD, Berr SS, Bryant RG, Daniel TM, de Lange EE, Downs JH 3rd, Erickson CJ, Happer W, Hinton DP, Kassel NF, Maier T, Phillips CD, Saam BT, Sauer KL, Wagshul ME. MR imaging and spectroscopy using hyperpolar ized ${ }^{129}$ Xe gas: preliminary human results. Magn. Reson. Med. 1997; 37: 809-815.

68. Driehuys B, Raidy T, Pollaro J. Hyperpolarized 129Xe MRI for functional assessment of radiation-induced lung injury. Int. J. Radiat. Oncol., Biol., Phys. 2005; 63: S460-S461.

69. Butler JP. Measuring surface-area-to-volume ratios in soft porous materials using laser-polarized xenon interphase exchange nuclear magnetic resonance. J. Phys. Condens. Matter 2002; 14: L297-L304.

70. Ruppert K, Brookeman JR, Hagspiel KD, Mugler JP 3rd. Probing lung physiology with xenon polarization transfer contrast (XTC). Magn. Reson. Med. 2000; 44: 349-357.

71. Dregely I, Mugler JP 3rd, Ruset IC, Altes TA, Mata JF, Miller GW, Ketel J, Ketel S, Distelbrink J, Hersman FW, Ruppert K. Hyperpolarized Xenon-129 gas-exchange imaging of lung microstructure: first case studies in subjects with obstructive lung disease. J. Magn. Reson. Imaging 2011; 33: 1052-1062.

72. Chang YV. MOXE: a model of gas exchange for hyperpolarized ${ }^{129} \mathrm{Xe}$ magnetic resonance of the lung. Magn. Reson. Med. 2013; 69: 884-890.

73. Chang YV, Quirk JD, Ruset IC, Atkinson JJ, Hersman FW, Woods JC. Quantification of human lung structure and physiology using hyperpolarized Xe. Magn. Reson. Med. 2013; 71: 339-344.
74. Ruppert K, Mata JF, Cai J, Read P, Sheng K, Altes TA, Wang H-TJ, Tobias WA, Cates GD, Brookeman JR, Hagspiel KD, Mugler JP 3rd. Detecting radiation-induced lung injuries using XTC MRI: initial findings. In: Proc ISMRM, 2007.

75. Patz S, Muradian I, Hrovat MI, Ruset IC, Topulos G, Covrig SD, Frederick E, Hatabu H, Hersman FW, Butler JP. Human pulmonary imaging and spectroscopy with hyperpolarized ${ }^{129}$ Xe at $0.2 T$. Acad. Radiol. 2008; 15: 713-727.

76. Fox M, Ouriadov A, Thind K, Hegarty E, Wong E, Hope A, Santyr G. Detection of radiation-induced lung injury in rats using dynamic hyperpolarized ${ }^{129}$ Xe magnetic resonance spectroscopy. Med. Phys. 2014; 41: 072302-1-9.

77. Ishii M, Emami K, Kadlecek S, Petersson JS, Golman K, Vahdat V, Yu J, Cadman RV, MacDuffie-Woodburn J, Stephen M, Lipson DA, Rizi RR. Hyperpolarized ${ }^{13} \mathrm{C}$ MRI of the pulmonary vasculature and parenchyma. Magn. Reson. Med. 2007; 57: 459-463.

78. Day SE, Kettunen MI, Cherukuri MK, Mitchell JB, Lizak MJ, Morris HD, Matsumoto S, Koretsky AP, Brindle KM. Detecting response of rat C6 glioma tumors to radiotherapy using hyperpolarized $\left[1{ }^{13} \mathrm{C}\right]$ pyruvate and ${ }^{13} \mathrm{C}$ magnetic resonance spectroscopic imaging. Magn. Reson. Med. 2011; 65: 557-563.

79. Kurhanewicz J, Vigneron DB, Brindle K, Chekmenev EY, Comment A, Cunningham $\mathrm{CH}$, Deberardinis RJ, Green GG, Leach MO, Rajan SS, Rizi RR, Ross BD, Warren WS, Malloy CR. Analysis of cancer metabolism by imaging hyperpolarized nuclei prospects for translation to clinical research. Neoplasia 2011; 13: 81-97.

80. Sandulache VC, Chen Y, Lee J, Rubinstein A, Ramirez MS, Skinner HD, Walker CM, Williams MD, Tailor R, Court LE, Bankson JA, Lai SY. Evaluation of hyperpolarized $\left[1-{ }^{13} \mathrm{C}\right]$-pyruvate by magnetic resonance to detect ionizing radiation effects in real time. PLoS One 2014; 9: e87031.

81. Pullinger $B$, Profka $H$, Ardenkjaer-Larsen JH, Kuzma NN, Kadlecek S, Rizi RR. Metabolism of hyperpolarized $\left[1-{ }^{13} \mathrm{C}\right]$ pyruvate in the isolated perfused rat lung - an ischemia study. NMR Biomed. 2012; 25: 1113-1118.

82. Thind $K$, Jensen MD, Hegarty $E$, Chen AP, Lim H, MartinezSantiesteban F, Van Dyk J, Wong E, Scholl TJ, Santyr GE. Mapping metabolic changes associated with early Radiation Induced Lung Injury post conformal radiotherapy using hyperpolarized ${ }^{13} \mathrm{C}$-pyruvate Magnetic Resonance Spectroscopic Imaging. Radiother. Oncol. 2014; 110: 317-322.

83. Jensen MD, Hrinivich WT, Jung JA, Holdsworth DW, Drangova M, Chen J, Wong E. Implementation and commissioning of an integrated micro-CTRT system with computerized independent jaw collimation. Med. Phys. 2013; 40: 081706.

84. Johnston CJ, Williams JP, Elder A, Hernady E, Finkelstein JN. Inflammatory cell recruitment following thoracic irradiation. Exp. Lung Res. 2004; 30: 369-382.

85. Mason RP. Transmembrane $\mathrm{pH}$ gradients in vivo: measurements using fluorinated vitamin B6 derivatives. Curr. Med. Chem. 1999; 6: 481-500.

86. Gillies RJ, Raghunand N, Karczmar GS, Bhujwalla ZM. MRI of the tumor microenvironment. J. Magn. Reson. Imaging 2002; 16: 430-450. 